had been unrecognised. As a result of his inspection, choice specimens from private collections in several instances have now been placed in local museums. Among the rarer and more unexpected of his finds are examples of Buddhist sculpture from Java at Edinburgh, Dublin, Elgin and Hawick, fine paintings of the Rajput, Kangra, and Moghul Schools at Halifax, Manchester and Edinburgh, and sculptures of the great Gandhara period and South Indian bronzes in many collections. Dr. Sita Ram, it is stated, is confident that without unduly depleting local collections, it is possible to get together ample material from Java and India now in the British Isles to provide for the central museum of Asiatic art and antiquities, which those who are interested in British national collections are convinced is an urgent need of the present time.

\section{Calendar Reform}

The International 'Fixed Calendar' League, 1 Regent Street, London, S.W.1, has issued a topical pamphlet entitled "How to Fix Easter and Establish Calendar Reform". The arguments for and against calendar reform bear some resemblance to the movement in favour of a 24-hour time system, which met with little encouragement from the public when it was given a trial by the B.B.C. last year. There is little solid, compelling argument in favour of either, though it would be a convenience in the long run to rationalise our methods of reckoning the hours of the clock and the days of the year. It is claimed that the fixation of Easter would result in great public convenience, and that the equalisation of the number of days in each month, and in each quarter, would simplify statistics based on monthly and quarterly returns. There are two rival schemes for calendar reform. In the first there are twelve months, each quarter containing $31+30+30$ days, and in the second thirteen months, each of 28 days. The stabilisation of the week and the month is to be obtained in either scheme by counting the 365th day in an ordinary year as Year Day, and by counting the 366th day in a Leap Year as Leap Day, neither day having a place in any week. The International Fixed Calendar League casts a shadow on the respectability and balance of its arguments by exhibiting an intemperate preference for the 13month plan as compared with the 12-month plan; it is claimed, for example, that the 13-month plan "would help research in science, health, etc." but that the 12 -month plan would not! It is extremely interesting to compare Pamphlet $E$ for general consumption, with Leaflet $L$, "Fixed Calendar Benefits for Labour" (which was not sent to Nature Office), in which the League indulges in an attempt to enlist the sympathies of the Labour movement in its scheme for calendar reform.

\section{Geographical Distribution of Unemployment}

In the issue of Planning dated March 26 (16 Queen Anne's Gate, London, S.W.1) some important facts relating to the geographical distribution of unemployment are emphasised with the aid of a diagram, wherein Great Britain is divided into two halves. The first half, consisting of the Midlands, South and South-West England, contains 6,319,000 insured persons between the ages of 16 and 64 years, while the second half, consisting of North England, Scotland and Wales, contains almost the same number, namely, 6,221,000. Yet the first half has less than 650,000 claimants to unemployment benefit and assistance, while the second half has nearly $1,300,000$, or more than two thirds of the total registered unemployed. If the comparison is confined to claimants for transitional payments and allowancesthat is, to the able-bodied unemployed coming under the Unemployment Assistance Board-the contrast is far more striking. Less than a quarter of these cases occur in the first or more prosperous half and more than three quarters in the depressed half. Moreover, as there are large areas which are fairly prosperous even in the second half, the real con. centration of the problem of able-bodied unemployment for long spells is far narrower than regional figures show. Another striking fact brought out is the relative insignificance of protracted unemployment among women workers.

\section{Printing by Wireless}

According to a report in The Times of April 20, a new instrument for wireless telegraphy, which will either handle the morse code or transmit and receive messages in plain letters, has recently been produced by Messrs. Siemens and Halske of Germany, and is being demonstrated at the London offices of Messrs. Siemens-Schuckert. The instrument can be operated by any ordinary wireless set with an output of one or two watts, the frequency of the output signal being adjusted to be 900 cycles per second. The mechanism consists of a short roller with a two-turn spiral or helix rotating over a paper tape and carbon paper, which are fed underneath. On the arrival of a signal, paper and carbon are lifted sharply up against the helix by a blunt knife-edge and, depending upon the duration of the blow, either a line or dot is printed. The duration of the dot is about $1 / 500$ of a second, while the system is capable of passing messages at a speed of about 50 words per minute. No very elaborate means of synchronism between transmitter and receiver is required, and the apparatus is almost entirely free from atmospheric and other forms of electrical interference. This new radio-telegraph printer is intended primarily for use in conditions where line-telegraphy is not possible, or where interference makes other methods of communication impossible. At a demonstration in London, signals were received from the Königswusterhausen Station in Germany, using 8 kilowatts and sending out its ordinary service of news.

\section{Science in Everyday Life and the Schools}

THE British Science Guild has recently organised a series of lectures on science which are intended to bring before the pupils of secondary schools some of the remarkable advances in scientific knowledge and in its applications to everyday life which are being 